\title{
Levelling the playing field in eSports - Dutch portrait rights in games
}

\author{
Kian Hsia* and Thijs van den Heuvel ${ }^{\star \star}$
}

\begin{abstract}
Last year the District Court of Amsterdam ruled that using the portrait of former Dutch soccer player Edgar Davids in the online video game 'League of Legends' is unlawful towards Edgar Davids. On the occasion of the World Cup 2014, Riot Games, the developer of the League of Legends, introduced four additional character skins that could be purchased by gamers. For the character 'Lucian', gamers could purchase the 'Striker' skin, and the Court first considered that Striker Lucian is a portrait of Edgard Davids. Furthermore, the Court considered that Edgar Davids has a reasonable interest to oppose the commercial exploitation of his portrait. The Court concluded that Striker Lucian is a portrait of Edgar Davids and Riot Games is acting unlawfully by disclosing Striker Lucian in the Netherlands. Besides, granting a declaratory decision and injunction, Riot Games was ordered to pay damages.
\end{abstract}

Keywords: portrait rights, the Netherlands, eSports, Article 10 ECHR, Article 8 ECHR, Article 21 Dutch Copyright Act, privacy, freedom of expression

\section{Introduction}

In 2017, the District Court of Amsterdam ruled in a case wherein the portrait of a former Dutch soccer player was used in a video game without his permission. ${ }^{1}$ This case report outlines the relevant facts of said case and provides a brief overview of portrait rights in the Netherlands.

\section{Edgar Davids v. Riot Games}

\subsection{Introduction}

Parties in the case were former Dutch soccer player Edgar Davids and Riot Games. The latter develops and exploits the computer game 'League of Legends' (hereinafter: 'LoL').

Edgar Davids played for inter alia Ajax, AC Milan, Juventus, FC Barcelona and for the Dutch national team. He is one of the most recognisable players of his generation due to this dreadlocked hair and protective googles that he also had to wear during matches due to glaucoma. His playing style was considered skilful, energetic and aggressive, hence his nickname 'The Pitbull'.

LoL is a virtual online video game in which gamers can play against each other. Each gamer chooses its own virtual character, also called 'champion'. The purpose in the standard version of LoL is that one team of gamers has to capture the base of the other team of gamers. The gamers can use a limited amount of free champions and additional champions can be purchased. Furthermore, it is also possible to change the appearance of a champion by purchasing a skin that is sold by Riot Games.

On the occasion of the World Cup 2014, Riot Games introduced four additional skins that relate to soccer. For the champion 'Lucian' gamers could purchase the 'Striker' skin (hereinafter: 'Striker Lucian'). For promotional purposes, Riot Games published more detailed illustrations of Striker Lucian. Shortly after the introduction of the new skins, messages popped up on forums as well as on social media, stating that the new skin showed strong resemblances with Edgar Davids. In response thereof, @RiotBeaconhawk posted on behalf of Riot Games - a tweet on Twitter showing a photo of Edgar Davids next to an illustration of Striker Lucian.

Edgar Davids instituted proceedings claiming that Riot Games infringes his portrait right by using Striker Lucian in LoL. The Court had to answer two questions to finally come to the conclusion that Edgar Davids' portrait has indeed been infringed by Riot Games:

1. Is Striker Lucian a portrait of Edgar Davids?

2. If the answer is yes, is the disclosure of Striker Lucian unlawful against Edgar Davids? 


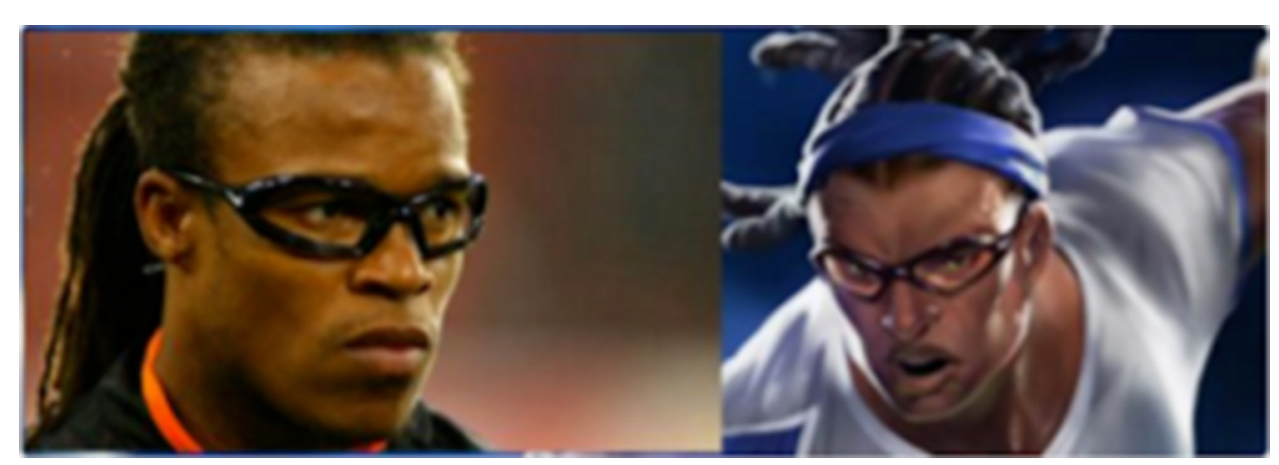

Figure 1 Photo of Edgar Davids next to an illustration of Striker Lucian

\subsection{Is Striker Lucian a portrait of Edgar Davids?}

First, the Court had to answer the question whether Striker Lucian is a portrait of Edgar Davids, as stipulated by Article 21 of the Dutch Copyright Act ('DCA'). The Court states first and foremost that when assessing that question the underlying technology is not decisive: a photo, a painting, or a digital display, e.g. a virtual character in a computer game, may all be qualified as a portrait. In assessing whether the character qualifies as a portrait, it is not only relevant how Striker Lucian is displayed in the game for the participating gamers, but also how he is shown in (other) published materials distributed by Riot Games. These other materials, like the above-mentioned illustrations that were published by Riot Games or the tweet showing a photo of Edgar Davids next to that of Striker Lucian, contain in general far more details. Details that are not clearly visible when playing the game (due to the fact that the characters as displayed in the game may contain less details or do not get noticed because of the speed of the game) do thus also play a role in answering the question whether Striker Lucian is a portrait of Edgar Davids.

In short, the Court considers that the skin Striker Lucian is a portrait of Edgar Davids, within the meaning of Article 21 DCA, because Striker Lucian has, just like Edgar Davids, a dark skin, a sporty posture, an aggressive playing style, black dreadlocks and sport goggles, all in combination with a soccer uniform.

According to the Court, the public would recognise in the more detailed illustrations of Striker Lucian, the portrait of Edgar Davids. This is already apparent from all the responses on Twitter. Moreover, this is enhanced by a tweet from Riot Games which mentions Edgar Davids as an inspiration for Striker Lucian. In addition, the skin was introduced around and on the occasion of the World Cup 2014. The latter also seems to play a role in the decision of the Court.

The Court further considers that a portrait per definition does not have to be similar to the person portrayed, because it is a portrait and not the person itself. What is relevant is whether the person is recognisable in the portrait. To assess whether there is a portrait or not, the context and the intention with which the portrait is used, should be taken into consideration.

\subsection{Is the disclosure of Striker Lucian unlawful towards Edgar Davids?}

After it has established that Stricker Lucian is a portrait of Edgar Davids, the Court subsequently considers whether Edgar Davids has a reasonable interest in opposing the disclosure of Lucian Striker, as stipulated by Article 21 DCA. This consideration concerns also the question if the disclosure of Striker Lucian is unlawful towards Edgar Davids. In that regard Article 8 ECHR (privacy) needs to be balanced against Article 10 ECHR (freedom of expression).

The Court points out that 'reasonable interest', as stipulated by Article 21 DCA, can relate to personal privacy interests as well as to commercial interests. Furthermore, protection provided by Article $8 \mathrm{ECHR}$ relates to private as well as professional or business activities.

The Court continues by considering that the person who is portrayed does not in all circumstances have to accept commercial exploitation of his acquired popularity in the exercise of his profession, by disclosure of his portraits without receiving a compensation for it. Sharing in the benefits of this commercial exploitation is in the view of the Court a reasonable interest as stated in Article 21 DCA.

In that regard, the Court considers that Edgar Davids has a so-called 'cashable popularity' as a former professional soccer player and hence a reasonable interest to oppose the disclosure of his portrait without receiving compensation. According to the Court, Riot Games profits from the portrait of Edgar Davids by offering the skin Striker Lucian against payment to gamers of LoL.

The Court considers that this reasonable interest of Edgar Davids outbalances Riot Games' appeal on Article 10 ECHR. The use of his portrait by Riot Games does 
not provide sufficient information about Edgar Davids or another subject matter to the interested audience (these are grounds on which the use of a portrait can, under circumstances, be justified). It is merely an optional embellishment of the game that can be purchased by the gamers and therefore Riot Games has mainly a commercial interest. Further, Riot Games had not offered any compensation and argued during proceedings that it does not see any reason to do so.

On basis of the foregoing, the Court concludes that in the balance of on the one hand Edgar Davids' interest to oppose the commercial exploitation of his portrait without compensation and on the other hand Riots Games' interest to offer an additional skin against payment in LoL, the interest of Edgar Davids outweighs that of Riot Games.

The Court ruled in an interim judgement that Striker Lucian is a portrait of Edgar Davids and that Riot Games is acting unlawfully by disclosing Striker Lucian in the Netherlands. Besides, granting a declaratory decision and injunction, the Court also ruled that Riot Games must pay damages. The amount of damages should correspond to the revenue and profit of the Riot Games Group in the Netherlands. Riot Games was ordered to file documents relating to their revenue and profits in the Netherlands that has been made with Striker Lucian in LoL.

\section{Portrait rights in the Netherlands}

\subsection{Dutch Copyright Act and the definition of a portrait}

In the Netherlands, portrait right protection is provided by the DCA. According to the Explanatory Memorandum to the DCA, the term 'portrait' refers to a representation of the face (with or without other parts of the body). However, in Dutch case law this definition has been stretched a bit. The Dutch Supreme Court ruled that it was sufficient, if the person portrayed was depicted in such a way that it became recognisable for others who know the person being portrayed. Even if the face is not shown, a photograph or other representation of a person might have this effect. ${ }^{2}$ Thus, recognisability for the intended audience is key, even in case of the use of a look-a-like. ${ }^{3}$

The DCA distinguishes two situations for portrait right protection: Articles 19 and 20 DCA relate to portraits that have been commissioned by the person portrayed, while Article 21 DCA relates portraits that have not been commissioned by or on behalf of the person portrayed. As described above, the Edgar Davids case concerned Article 21 DCA and reads as follow:

If a portrait is made without the author having been commissioned by or on behalf of the person portrayed, or for his benefit, the rightholder is not permitted to disclose the portrait to the public if there is a reasonable interest opposing disclosure on the part of the person portrayed or, after his death, one of his relatives. (Emphasis added by author)

The open concept of 'reasonable interest' has been further developed in Dutch case law. Originally it was meant to protect persons against unlawful publications. The legislator intended to protect the privacy interests of the person portrayed. Later on, commercial interests of the person portrayed could also be considered a reasonable interest. Both interests need to be balanced against the freedom of expression.

\subsection{Privacy}

As said, privacy interests can be considered a reasonable interest within the meaning of Article 21 DCA. Anyone famous or not - may oppose the use of their portrait if it causes a serious breach of their privacy. ${ }^{4}$

A consideration has to be made between Articles 8 and 10 ECHR. In that consideration, factual circumstances must be taken into account, for example, the place and manner in which the picture is created, the nature and extent of the intimacy in which the person portrayed is shown, the nature of the picture, the context of the publication, the correctness of the other information provided in the article as well as the social interest, the news value or the informative value of the publication thereof. ${ }^{5}$

\subsection{Commercial interest}

Another form of reasonable interest within the meaning of Article 21 DCA relates to commercial interests. This is relevant when the fame or popularity of the person portrayed is of such nature that commercial exploitation of his portrait is possible. ${ }^{6}$ In other words, the person portrayed has a so-called 'cashable popularity'.
2 Dutch Supreme Court, 30 October 1987, NJ 1988, 277 (Naturiste); Dutch Supreme Court, 2 May 2003, NJ 2004, 80 (Nielsen \& IPA/Storms Factory; Breekijzer).

3 District Court Amsterdam 6 December 2017, ECLI:NL:RBAMS:2017:8990 (Mavic/Karakter Uitgevers); District Court Amsterdam 6 September 2017, ECLI:NL:RBAMS:2017:6395 (Mavic/Picnic).
4 Dutch Supreme Court, 21 January 1994, NJ 1994,473 (Moordenaar G.J. Heijn).

5 Dutch Supreme Court, 1 July 1998, ECLI:NL:HR:1988:AB7688 (Vondelpark); Dutch Supreme Court, 14 June 2013, ECLI:NL:HR:2013:CA2788 (Cruijff/ Tirion).

6 Dutch Supreme Court, 19 January 1979, NJ 1979, 383 ('t Schaep met vijf poten). 
Besides commercial reasons, a person portrayed having 'cashable popularity', may still object to publication on the basis of his privacy. This may be the case if a certain famous person does not want to be linked to a particular product or service. In that case, they can object on the basis of commercial and/or privacy interests.

The commercial interest of the person portrayed also needs to be balanced against the freedom of expression. In that assessment, the news value or informative value of the publication, the nature of the pictures and the context of the publication must be taken into account. Furthermore, it is important if the person portrayed has been offered a reasonable compensation. ${ }^{7}$ Whether compensation is reasonable depends on the factual circumstances, taken into account the extent of the fame or popularity of the person portrayed. Furthermore, the amount of the compensation must conform to the value of the commercial interest of the person portrayed in the economic traffic.

\section{Conclusion}

When a portrait of a person has been disclosed without permission, the DCA provides portrait right protection on the basis of privacy and/or commercial interest(s). In case of Edgar Davids v. Riot Games, the Court first points out that Striker Lucian is a portrait of Edgar Davids. It comes to this conclusion, because Striker Lucian and Edgar Davids show strong resemblances, taken also into account the publications and tweets that have been published by Riot Games.

Furthermore, the Court concludes that in the balance of on the one hand Edgar Davids' interest to oppose the commercial exploitation of his portrait without compensation and on the other hand Riots Games' interest to offer an additional skin against payment in LoL, the interest of Edgar Davids outweighs that of Riot Games. The Court seems to rely heavily on the fact that no financial compensation was offered by Riot Games to Edgar Davids. Thus, the commercial interest of Edgar Davids was sufficient to oppose the disclosure within the meaning of Article 21 DCA.

In this interim judgement, the Court ruled that Striker Lucian is a portrait of Edgar Davids and that Riot Games is acting unlawfully by disclosing Striker Lucian in the Netherlands. Besides, granting a declaratory decision and injunction, the Court also ruled that Riot Games must pay damages. The amount thereof is to be decided on the basis of the revenue and profit that has been made by the Riot Games Group in the Netherlands by exploiting Striker Lucian in LoL. 